\title{
Revealing research preferences in conservation science
}

\author{
Jasper Montana, Chris Sandbrook, Ellen Robertson and Melanie Ryan
}

\begin{abstract}
Conservation researchers are increasingly drawing on a wide range of philosophies, methods and values to examine conservation problems. Here we adopt methods from social psychology to develop a questionnaire with the dual purpose of illuminating diversity within conservation research communities and providing a tool for use in cross-disciplinary dialogue workshops. The questionnaire probes the preferences that different researchers have with regards to conservation science. It elicits insight into their motivations for carrying out research, the scales at which they tackle problems, the subjects they focus on, their beliefs about the connections between nature and society, their sense of reality as absolute or socially constituted, and their propensity for collaboration. Testing the questionnaire with a group of 204 conservation scientists at a student conference on conservation science, we illustrate the latent and multidimensional diversity in the research preferences held by conservation scientists. We suggest that creating opportunities to further explore these differences and similarities using facilitated dialogue could enrich the mutual understanding of the diverse research community in the conservation field.
\end{abstract}

Keywords conservation social science, interdisciplinary research, preferences, questionnaire, reflexivity, research design, social psychology

Supplementary material for this article is available at https://doi.org/10.1017/So03060531900067X

\section{Introduction}

R esponding effectively to the unabated loss of species Rand ecosystems requires conservation researchers to work across disciplinary boundaries, think at multiple scales, and engage with diverse stakeholders. A growing awareness of the social and political dimensions of

JaSPer MONTana (Corresponding author) School of Geography and the Environment, University of Oxford, South Parks Road, Oxford, OX1 3QY, UK E-mail jasper.montana@ouce.ox.ac.uk

Chris SANDBROoK Department of Geography, University of Cambridge, Cambridge, UK

ElLen RoberTson Department of Psychology, University of Cambridge, Downing Street, Cambridge, UK

Melanie Ryan Luc Hoffmann Institute, WWF International, Gland, Switzerland

Received 17 December 2018. Revision requested 10 April 2019.

Accepted 4 June 2019. First published online 22 October 2019. biodiversity loss has shifted conservation science from a discipline dominated by the natural sciences into a multi-, inter- and trans-disciplinary endeavour (Mascia et al., 2003; Sandbrook et al., 2013; Bennett et al., 2017). Conservation scientists are adopting a more diverse range of approaches and are increasingly collaborating across disciplines to respond to conservation problems (Colloff et al., 2017). However, working across disciplines in conservation has known conceptual challenges, including competing theories of knowledge, disciplinary prejudices and difficulties in interdisciplinary conversation (Fox et al., 2006; Adams, 2007; Eigenbrode et al., 2007; Sievanen et al., 2012; Pooley et al., 2014; Bennett et al., 2016). Overcoming these requires an investment in initiatives that improve mutual understanding of disciplinary diversity (Campbell, 2005). As conservation science becomes increasingly pluralist in its methods, there is therefore scope for experimenting with new ways to examine diversity and thereby find common meaning across interdisciplinary teams.

The field of social psychology may offer some insight. Scholarship in psychology has been increasingly recognized for its potential to contribute to conservation research and practice (Saunders et al., 2006; Selinske et al., 2018). Work in this field to date has focused on the attitudes, and to a lesser extent behaviours, of societies and stakeholders with respect to conservation (St John et al., 2010). However, there is also scope for the tools of social psychology to be brought to investigate the attitudes and behaviours of research communities. Scholars from the philosophy of science have previously developed and tested approaches to overcome disciplinary divides in the environmental sciences. A previously developed toolbox for philosophical dialogue, for example, offers an approach to probing personal attitudes towards research and generating philosophical dialogue within research teams through responding to and discussing a set of open-ended questions (Eigenbrode et al., 2007). This toolbox approach has been widely tested in toolbox workshops, in which research collaborators are encouraged to share and discuss their conceptual worldviews with collaborators (O'Rourke \& Crowley, 2013). However, the toolbox approach is a teambased method that requires a diversity of participants to be in the room and to engage sufficiently with the activity to support its success. Furthermore, it is predicated on qualitative and interpretive methods, which may not align with the expectations of some participants more accustomed to quantitative approaches.

Here we set out to examine the potential for developing a conservation-specific tool that could analyse diversity 
quantitatively within the conservation research community and also be used to help multi-disciplinary teams of conservation researchers understand each other better. Drawing on methods from social psychology and building on insight from the toolbox approach, we develop a questionnaire that reveals research preferences in conservation science. Research preferences are understood as the personal attitudes held by researchers with regards to the conduct of their research. In the field of psychology, such attitudes are understood to define the way people form subjective understandings of the world around them and how that understanding is reflected in behaviour (Eiser, 1986). The use of questionnaires to probe the relationship between attitudes and behaviour has been widely applied in business management settings, through approaches such as personality-type questionnaires that examine how preferences manifest in different workplaces (Blackford, 2010; Bridges, 2010). Bringing these approaches to the field of conservation science, we develop a short questionnaire that probes the preferences that different researchers have with regards to conservation science. It elicits insight into their motivations for carrying out research, the scales at which they tackle problems, the subjects they focus on, their beliefs about the connections between nature and society, their sense of reality as absolute or socially constituted, and their propensity for collaboration. The questionnaire can be used by individual researchers for personal selfreflection or to analyse diversity within large groups, and can be combined with facilitated dialogue to support mutual understanding within cross-disciplinary teams.

\section{Methods}

This research was carried out in two interlinked stages during January-April 2017. In the first stage we developed and validated a questionnaire (also known as a psychometric scale) to discern research preferences (factors in psychological terms) within a conservation community. To do so we used written questions to identify a respondent's preferences for different approaches to conservation research. The second stage used the results to examine the relationship between these research preferences and the self-identification of respondents as natural and/or social scientist. We analysed the questionnaire results and demographic data within the sample population, composed mostly of participants at the Cambridge Student Conference on Conservation Science.

We identified an initial set of broad behaviours or attitudes to conservation research from literature and exploratory interviews with researchers in conservation science selectively sampled from zoology, geography, plant sciences, and history and philosophy of science. This process yielded a list of six possible factors of interest that reflected behaviours or attitudes towards conservation research (Table 1 ).
Firstly, as in all fields (Eigenbrode et al., 2007), conservation researchers are guided by particular motivations that relate to the aims driving their work. Conservation science is often described as a mission-driven discipline (Meine et al., 2006; Mace, 2014) in which research is generally directed towards actions that 'establish, improve or maintain good relations with nature' (Sandbrook, 2015, p. 565). However, there are likely to be differences in the extent that conservation researchers are motivated by achieving conservation outcomes or other kinds of impact. Outcomes and impact are broad concepts, and will be interpreted differently by different researchers. They could range from conceptual outcomes, such as changing the way issues are theorized, to substantive ones, such as changing a specific conservation practice. Such motivations sit alongside other reasons for doing research such as curiosity or professional development.

Secondly, conservation research often involves methods that conform to particular scales of analysis, from the global to the local (Margulies et al., 2016). Research may focus on synthesis research or seek to identify generalizable trends, or it may closely examine case studies to identify localized specifics (Cox, 2015). These tendencies between the general and the specific are likely to reflect distinct beliefs about the universalism of science and the localized contingency of research (Douthwaite et al., 2003; Sutherland et al., 2017).

Thirdly, as the field of conservation science has developed there have been notable shifts in the framing of conservation science with regards to the relative focus directed towards people and nature (Mace, 2014). Depending on their personal and institutional backgrounds, conservation researchers are therefore likely to have distinct preferences for dedicating their attention to species and ecosystems, or humans and their institutions.

Fourthly, alongside the focus of research, there are variations in the way researchers view the relationship between the traditional categories of nature and society. Increasingly, the concept of socioecological systems is a prominent framework for thinking about the interconnectedness between social and ecological systems in environmental management (Berkes \& Folke, 1998; Díaz et al., 2015). In parallel, social theory has sought to break down the dualism of nature and society by emphasizing the hybrid networks of humans and non-humans that underpin both domains (Latour, 1993; Whatmore, 2002). Hence, there is likely to be variation amongst researchers about the extent to which nature and society are seen as hybridized or clearly distinct domains.

Fifthly, extensive research in the philosophy of science has examined the alternative worldviews that lead some researchers to believe in the existence of an external reality that is knowable through scientific research, and others who accept the existence of many local socially constituted realities existing in the minds of different people (Proctor, 1998). 
These realist and relativist perspectives, respectively, are recognized as important operating distinctions in the environmental sciences, including conservation (Moon \& Blackman, 2014).

Sixthly, there are current debates about whether or not engaging stakeholders during research, rather than at the end of research, is useful for conservation outcomes ( $\mathrm{Nel}$ et al., 2016; Sutherland et al., 2017). As such, there probably is variation in the degree to which conservation researchers seek to engage in pragmatic collaboration with stakeholders or work independently in framing research questions and processes.

In psychological terms, we considered the research preferences of respondents to be factors that could be understood through individual measurements (response to questions) and thus statistically analysed. For each factor, we drafted 8-10 questions for inclusion in the questionnaire. These were counterbalanced so that half represented endorsement of one extreme of the factor and the other half represented endorsement of its opposite. For example, questions pertaining to the subject focus of research included statements indicating a focus on species and ecosystems (e.g. 'In my research, I am primarily interested in the dynamics of animals, plants and their ecosystems') counterbalanced with those indicating a focus on humans and their institutions (e.g. 'The primary goal of my research is to understand humans and their institutions better'). This ensured a balance of positive and negatively termed questions and resulted in the development of a list of 50 questions.

This questionnaire was piloted with a small focus group to test the extent to which the questions made sense and adequately addressed the construct of research preferences they were intended to measure, so that we could revise the questions if required. Participants involved in the focus group $(n=7)$ were selectively sampled from the University of Cambridge Conservation Research Institute to include a range of genders $(\operatorname{men}=4$, women $=3)$, disciplines (zoology $=4$, geography $=2$, plant sciences $=1)$ and world regions (Europe $=4$, South America $=2$, Africa $=1$ ). The focus group session lasted for 1 hour, during which participants were asked to complete the questionnaire and report any misunderstandings or reactions. We then made minor revisions to the balance and wording of questions.

In March 2017 we posted the revised questionnaire online, on the Qualtrics platform. The order of questions was randomized and demographic questions on age, gender, discipline, world region, and self-identification as a natural and/or social scientist were added. We did not adopt a fixed definition of these categories, but instead allowed respondents to self-identify. Participants were invited to complete the questionnaire between March and April 2017 by emails sent to the mailing lists of the attendees of the 2016 and 2017 Student Conferences on Conservation Science and within the University of Cambridge Conservation Research
Institute, and posters and fliers inviting responses were distributed at the 2017 conference. The opportunity to enter a prize draw for a gift card was made available to all participants. The responses provided the data through which the questionnaire was statistically validated using factor analysis.

\section{Factor analysis}

The statistical validation of the questionnaire was carried out through factor analysis, which modelled the interrelationships between the questions in the questionnaire based on collected responses, to identify a smaller set of factors each representing a different research preference. Before conducting the exploratory factor analysis, we removed some questions (items in psychological terms): six because they correlated with one or fewer items, and one that correlated at 0.2 level with two items (indicating a weak relationship and an unlikely fit in a potential factor solution). Then exploratory factor analyses were performed with the principle axis factoring extraction method, with the oblique (direct oblimin) rotation. The screen plot showed an inflection at c. 6-8 factors, which corresponded with the a priori factor structure. Therefore, most analyses were set to extract 6-8 factors. Coefficients were suppressed below 0.3 , as low coefficients would demonstrate too weak a relationship between the item and the factor (Field, 2009). With these parameters, we chose a factor solution based on the criterion that all factors consisted of at least three variables that loaded above 0.3 , while retaining as many of the original variables as possible. To arrive at this solution, items were removed if they consistently did not load onto any factors or if they cross-loaded evenly onto two or more factors. The final factor solution had a KaiserMeyer-Olkin measure of sampling adequacy of 0.622 , demonstrating that the sample is acceptable, although the analysis would benefit from a larger sample size (Kaiser, 1974). Bartlett's test of sphericity $\left(\chi^{2}(595.03)=171\right.$, $\mathrm{P}<0.001)$ indicated that correlations between items were sufficiently large for factor analysis (Field, 2009). Cronbach's $\alpha$ test for reliability is included in the table of factor loadings. The final factor solution with six factors and 19 associated variables became the validated questionnaire. We reviewed the factors and associated variables to check for meaningful relations, assigned names and developed complementary pairs for communication of results.

\section{Demographic analysis}

To examine any differences between respondents that selfassigned into the categories of natural scientist, social scientist, and both natural and social scientist, we compared the mean scores of the factors in the validated questionnaire across these categories. Participants had been given the 
TABLE 1 Complementary pairs and their descriptions based on the validated questionnaire exploring research preferences in conservation science.

\section{Impact driven}

This approach to research is driven by a desire to achieve impact or conservation outcomes \& the belief that conservation research should always mobilize action.

\section{Local specifics perspective}

This perspective finds the details of specific research sites more interesting than general trends.

\section{Autonomous idealist}

This approach to research is likely to be independent from collaborators with opposing perspectives, as these are thought to compromise efficiency \& integrity of research.

\section{Human-focused research}

This approach to research is primarily interested in the dynamics of humans \& their institutions.

\section{Relativist}

This worldview sees reality as something that is constructed in the minds of individual humans \& is unique to each.

\section{Nature \& society separation}

This worldview sees nature as clearly distinct from society \& considers it appropriate to study natural \& social systems as independent entities.

\section{Non-impact driven}

This approach to research is not concerned with achieving conservation impact or outcomes, \& may be motivated by many other factors such as curiosity or professional success.

General trends perspective

This perspective is more interested in broad scale processes \& synthesis research than what happens in particular cases.

\section{Pragmatic collaborator}

This approach to research is likely to be collaborative, \& will involve work with stakeholders, even those that the researcher disagrees with.

\section{Nature-focused research}

This approach to research is primarily interested in the dynamics of animals, plants \& their ecosystems.

Realist

This worldview considers that there is only one reality, which can be directly studied \& known through research.

\section{Nature-society hybridity}

This worldview sees nature \& society as hybrid entities made up of both human \& non-human elements that can never be truly separated. option to answer 'neither', but because only nine people chose this option, these were coded as missing for the analyses. We used a one-way analysis of variance with bootstrapping (with 1,00o resamples). As the data were nonnormal, bootstrapping was used for the parametric tests. In cases where significant difference was identified, we ran post-hoc tests with Hochberg's GT2 because of the difference in sample sizes between the groups.

\section{Results}

The questionnaire received 204 responses that were sufficiently complete to be included in the analysis. This included 178 responses from the 349 conference participants invited (a response rate of 51\%), and 26 from wider advertising.

\section{Factor analysis}

The factor analysis produced a statistically grounded factor solution of six factors, each representing a different research preference. These factors each contained three variables, except for one that had four, for a total of 19 variables (Supplementary Table 1). This provided the basis of the validated questionnaire, with 19 questions corresponding to six research preferences reflecting different philosophies, methods and values. For questionnaire respondents, a high score in relation to a given factor indicated a tendency towards a given research preference (left-hand column of Table 1), with the right-hand column being a complementary alternative. Although in some cases the complementary alternative was self-evident, for example the distinction between realism and relativism, in others the complementary alternative could only be recognized for what it was not, such as the extent that research is impact- or outcome-driven. The characteristics of each factor were developed by giving them short descriptions to aid the presentation and interpretation of results. These descriptions were derived from key words in the validated list of questions, as well as interpretation of the meaning of each factor by the research team. Although the language of the questions could have been interpreted in different ways by different respondents, the statistical analysis of the 204 respondents ensured that the questions and subsequent factors were clustered in a way that was consistently meaningful to these respondents and showed sufficient within-factor variation to be suitable markers of distinction between them. We developed a spider diagram for visual display of the six factors (Fig. 1), and a proposed workshop structure for a group activity and a printable version of the self-score questionnaire (Supplementary Materials 1 \& 2, respectively).

\section{Demographic analysis}

Of the 204 respondents 191 provided demographic data that could be used for a comparative analysis between those that self-identified as a natural scientist, social scientist or both (Supplementary Table 2). Each of these groups showed wide variability in their responses for each of the six factors (Fig. 1). When responses from these groups were compared 
(a) Natural scientist only

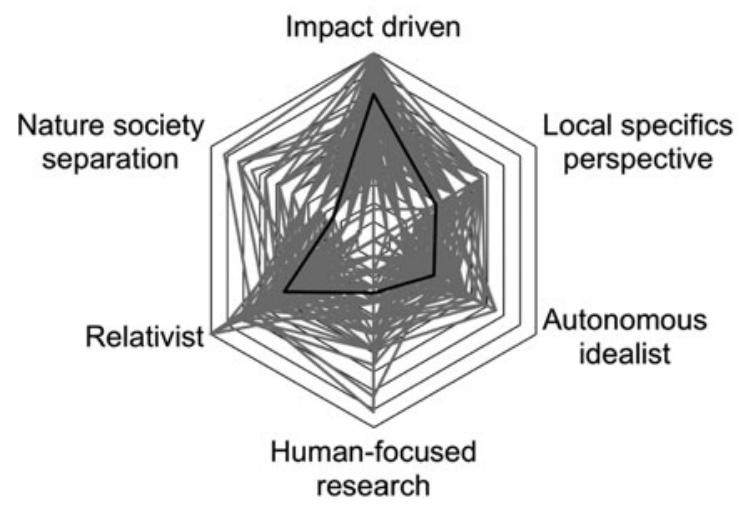

(b) Both natural and social scientist

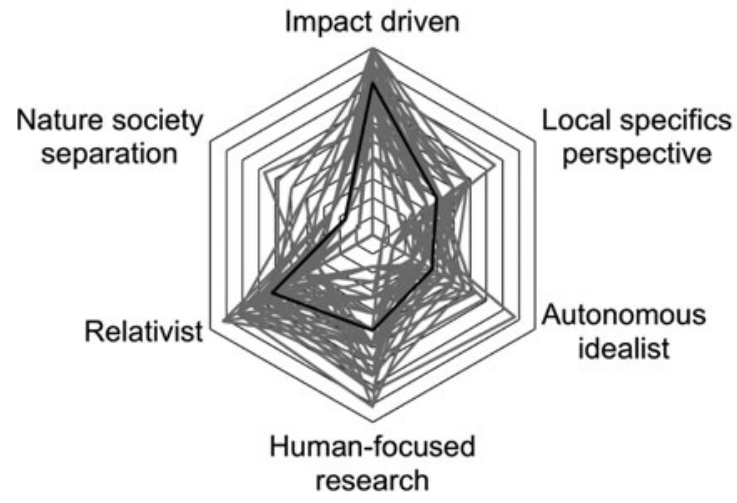

(c) Social scientist only

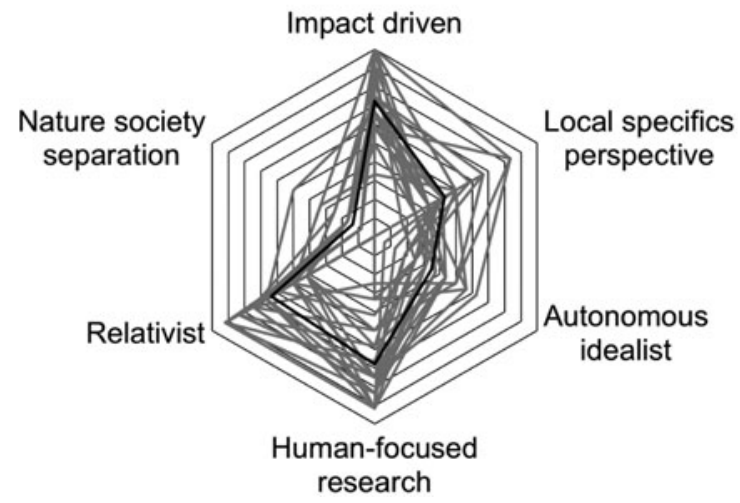

FIG. 1 Spider diagrams of results for respondents identifying as (a) natural scientist only, (b) both natural and social scientist, and (c) social scientist only. Grey lines represent individual respondents to show spread, and the black line represents the average of all responses.

across the factors, there were significant differences between the categories across some but not all of the six factors (Fig. 2). Although there was no significant relationship with tendencies for impact driven $(F(3,196)=1.573$,
$\mathrm{P}>0.05)$, general trends perspective $(F(3,196)=0.498$, $\mathrm{P}>0.05)$ or autonomous idealist $(F(3,196)=0.093$, $P>0.05)$, there was a significant relationship with identifying as natural scientist, social scientist, or both, on humanfocused research $(F(3,196)=33.863, \mathrm{P}<0.001)$, relativist $(F(3,196)=7.319, \mathrm{P}<0.001)$ and nature and society separation $(F(3,196)=3.487, \mathrm{P}<0.05)$.

Post-hoc tests, with Hochberg's GT2, showed that for human-focused research, social scientists $(M=3.79$, $\mathrm{SD}=0.78)$ scored significantly higher $(\mathrm{P}<0.001)$ than people who identified as both $(M=3.03, \mathrm{SD}=0.92)$ and than those who identified as natural scientists $(M=2.12$, $\mathrm{SD}=0.77$ ). A higher score demonstrates greater interest in people and society than in ecosystems, and those who identified as both also scored significantly higher $(\mathrm{P}<0.001)$ than natural scientists. For relativist tendencies, social scientists $(M=3.67, \mathrm{SD}=0.70)$ scored significantly higher $(\mathrm{P}<0.05)$ than natural scientists $(M=3.22, \mathrm{SD}=0.75)$, and the both category $(M=3.48, \mathrm{SD}=0.69)$ scored higher than the natural scientists, but this difference was not significant. For nature and society separation, natural scientists $(M=1.99, \mathrm{SD}=0.87)$ scored significantly higher $(\mathrm{P}<0.05)$ than people who identified as both $(M=1.68, \mathrm{SD}=0.62)$, and although both scored higher than social scientists $(M=1.56, \mathrm{SD}=0.53)$, occupying an intermediate position, this difference was not significant. For this factor the difference between natural scientists and social scientists was, however, close to significance, at $\mathrm{P}=0.051$.

\section{Discussion}

This research had the dual purpose of creating a questionnaire that could analyse diversity in the research preferences of conservation research communities and also be used to help multi-disciplinary teams of conservation researchers better appreciate each other's approaches to research. The results illustrate the potential of this questionnaire to examine diversity within communities of conservation researchers. The questionnaire identified a diversity of research preferences both within the categories of natural and social scientist, and between them. In general, the results show a statistical difference between the categories of social and natural sciences for the factors of human-focused research, nature and society separation, and the relativist worldview. But the results also show that respondents from these self-defined categories also exhibit high variability within the same factors. Self-identifying as a natural scientist did not preclude one from achieving a high score on the relativist factor, and vice versa. This perhaps reflects the known diversity of disciplinary approaches (from theoretical biology to bioinformatics, and from anthropology to economics) within the broad categories of the natural and social sciences in conservation (Bennett et al., 2017), and reinforces 


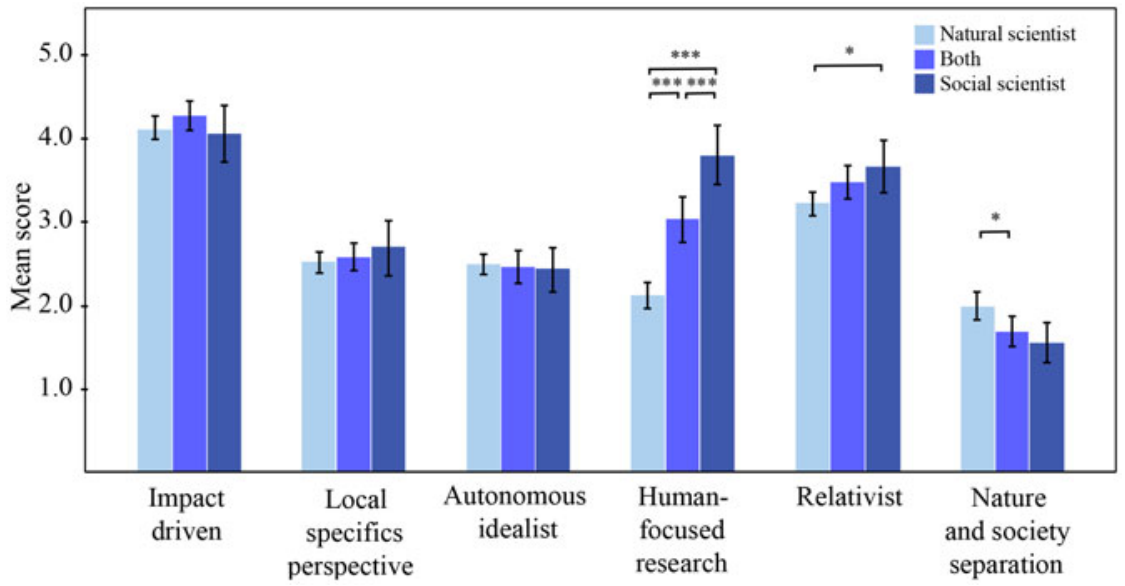

FIG. 2 Difference in mean score $( \pm 95 \%$ confidence interval) of questionnaire respondents that identified as natural scientist, both natural and social scientist, or social scientist across all six factors (Table 1). Asterisks indicate differences significant at $\mathrm{P}<0.05\left(^{*}\right)$ and $\mathrm{P}<0.001$ $(* * *)$. the limitations of applying this binary distinction. The existence of marked within-group variability across the multidimensional factors of this questionnaire raises questions about the extent to which the categories of natural scientist and social scientist offer meaningful distinctions in positioning researchers in the field of conservation research. Although these terms remain prominent in organizations such as the Society for Conservation Biology (Bennett et al., 2016), our findings suggest that more multidimensional measures of researcher diversity would be useful.

Further examination of what the self-assigned categories of natural scientist, social scientist and both mean to the questionnaire respondents may help elucidate how sense of researcher identity provided by these categories emerges through disciplinary training and how this influences philosophical positions. Demographic data suggested that the majority of respondents entered the field from single disciplinary contexts. Specifically, biology, botany, computer science, ecology, mathematics and zoology were prominent entry routes for those identifying as natural scientists, but also those identifying as both natural and social scientists. Further exploration of the ways that early training of conservation researchers reinforces particular philosophies, methods and values in examining conservation problems would be a fruitful avenue of future research.

Drawing on the approach developed here, further research could apply this questionnaire to analyse the composition of both large and small research groups in a range of settings. It could be used to understand research preference diversity within a collaborative research project, or it could be applied as a longitudinal measure, to see if individual tendencies change over time in response to education or experience in interdisciplinary collaborations.

In addition to being an analytical tool, the questionnaire and the personal profiles that can be produced from it could have application as tools for building researcher capacity in interdisciplinary collaboration. In line with previous scholarship on the toolbox approach (Eigenbrode et al., 2007; O'Rourke \& Crowley, 2013), the questionnaire presented here could be used alongside carefully facilitated dialogue to support structured philosophical conversation. Workshops would allow respondents to both interrogate their own results and question the ways in which different preferences may shape their research collaborations. In this way, participants can learn from each other about why different approaches to research matter in conservation science.

The application of the questionnaire as a tool for reflection and facilitated dialogue, however, requires careful consideration about the ways in which different conservation researchers will relate to the questionnaire as one approach (among many) to responding to the previously highlighted conceptual challenges of multi-, inter-, and trans-disciplinary work in conservation. Although the quantitative and categorical nature of the questionnaire is likely to appeal to those researchers who favour more positivist approaches, interpretive social scientists may feel that the questionnaire process and results are unable to reflect the complex philosophical position that they and those around them bring to research in practice (for further exploration of research philosophies in conservation, see Moon \& Blackman, 2014). The questionnaire as a tool for reflection and dialogue will therefore need to be applied with care to take into account these diverse positions and many others.

The results of the questionnaire are intended to be indications of fluid tendencies within researcher preferences that can and will change over time. In this way, the questionnaire provides no normative position on where any individual or group positions sit. It is descriptive rather than prescriptive, and is not intended to create new dualisms between the extremes of different factors. For these reasons, the results are intended to be displayed as numerical positions in a spider diagram, along a spectrum, rather than assigned as a fixed category. Although the contested 
nature of concepts and terms used in the questionnaire may lead some respondents to feel that the factors do not accurately reflect their worldviews we seek to emphasize that such reflections are perfectly valid. The sharing and discussion of these concerns through a group dialogue process is an intended outcome of this work. To further explore the challenges of applying the questionnaire methodology for this purpose, future research could empirically examine the way in which different researchers relate to the questionnaire as a tool for reflection and facilitated dialogue. As part of this, it would be valuable to understand the extent to which the questionnaire meaningfully reflects the general preferences of respondents, or if a different approach is needed to capture the preferences of increasingly pragmatic researchers that are accustomed to adapting their research methods and approaches to the changing nature of research problems.

Nevertheless, there is ample scope for further research into the potential contributions that social psychology could offer the conduct of conservation research itself. Further testing is required to examine whether facilitated dialogue about disciplinary differences can change a researcher's understanding of themselves and others in collaborative teams. Previous research suggests that critical examination of worldviews and philosophies can transform individual, organizational and group capacity as well as inform the ways in which other skills are deployed in pursuit of conservation science goals (O'Brien et al., 2013; Binder et al., 2015). Interventions that challenge researchers to externalize and justify their research preferences, such as the questionnaire presented here, are opportunities to build a greater appreciation for the range of different approaches to research that coexist within the conservation field.

Acknowledgements We thank two anonymous reviewers for comments, Jonathan Hutton for contributing to the initial conceptual development, and the organizers of the Cambridge Student Conference on Conservation Science and members of the University of Cambridge Conservation Research Institute, who assisted with the recruitment of participants. This research received no specific grant from any funding agency, or commercial or not-for-profit sectors.

Author contributions Study design: JM, CS, ER, MR; data collection: JM; data analysis: ER, JM; writing: JM, ER, MR, CS.

\section{Conflicts of interest None.}

Ethical standards This research abided by the Oryx guidelines on ethical standards and was conducted with ethical approval from the Department of Geography, University of Cambridge (Research Ethics Assessment ID 402, approved 9 February 2017).

\section{References}

Adams, W.M. (2007) Thinking like a human: social science and the two cultures problem. Oryx, 41, 275-276.
Bennett, N.J., Roth, R., Klain, S.C., Chan, K., Christie, P., Clark, D.A. et al. (2017) Conservation social science: understanding and integrating human dimensions to improve conservation. Biological Conservation, 205, 93-108.

Bennett, N.J., Roth, R., Klain, S.C., Chan, K.M.A., Clark, D.A., Cullman, G. et al. (2016) Mainstreaming the social sciences in conservation. Conservation Biology, 31, 56-66.

Berkes, F. \& Folke, C. (1998) Linking Social and Ecological Systems: Management Practices and Social Mechanisms for Building Resilience. Cambridge University Press, Cambridge, UK.

Binder, C.R., Absenger-Helmli, I. \& Schilling, T. (2015) The reality of transdisciplinarity: a framework-based selfreflection from science and practice leaders. Sustainability Science, 10, $545-562$.

BLACKFORD, S. (2010) A qualitative study of the relationship of personality type with career management and career choice preference in a group of bioscience postgraduate students and postdoctoral researchers. International Journal for Researcher Development, 1, 296-313.

BRIDges, W. (2010) The Character of Organizations: Using Personality Type in Organization Development. Davies-Black, London, UK.

CAmpbell, L.M. (2005) Overcoming obstacles to interdisciplinary research. Conservation Biology, 19, 574-577.

Colloff, M.J., Lavorel, S., van Kerkhoff, L.E., Wyborn, C.A., Fazey, I., Gorddard, R. et al. (2017) Transforming conservation science and practice for a postnormal world. Conservation Biology, 31, 1008-1017.

Cox, M. (2015) A basic guide for empirical environmental social science. Ecology and Society, 20, 63.

Diaz, S., Demissew, S., Joly, C., Lonsdale, W.M. \& Larigauderie, A. (2015) A Rosetta stone for nature's benefits to people. PLOS Biology, 13, e1002040.

Douthwaite, B., Kuby, T., van de Fliert, E. \& Schulz, S. (2003) Impact pathway evaluation: an approach for achieving and attributing impact in complex systems. Agricultural Systems, $78,243-265$.

Eigenbrode, S.D., O’Rourke, M., Wulfhorst, J.D., Althoff, D.M., Goldberg, C.S., Merrill, K. et al. (2007) Employing philosophical dialogue in collaborative science. BioScience, 57, 55-64.

Eiser, J. (1986) Social Psychology: Attitudes, Cognition and Social Behaviour. Cambridge University Press, Cambridge, UK.

FIELD, A. (2009) Discovering Statistics Using SPSS. 3rd edition. Sage Publications, London, UK.

Fox, H.E., Christian, C., Nordby, J.C., Pergams, O.R.W., Peterson, G.D. \& Pyke, C.R. (2006) Perceived barriers to integrating social science and conservation. Conservation Biology, 20, $1817-1820$.

Kaiser, H.F. (1974) An index of factorial simplicity. Psychometrika, $39,31-36$.

Latour, B. (1993) We Have Never Been Modern. Harvard University Press, Cambridge, USA.

MACE, G. (2014) Whose conservation? Science, 345, 1558-1560.

Margulies, J.D., Magliocca, N.R., Schmill, M.D. \& Ellis, E.C. (2016) Ambiguous geographies: connecting case study knowledge with global change science. Annals of the American Association of Geographers, 106, 572-596.

Mascia, M.B., Brosius, J.P., Dobson, T.A., Forbes, B.C., Horowitz, L., McKean, M.A. et al. (2003) Conservation and the social sciences. Conservation Biology, 17, 649-650.

Meine, C., SoulÉ, M. \& Noss, R.F. (2006) "A mission-driven discipline": the growth of conservation biology. Conservation Biology, 20, 631-651. 
Moon, K. \& Blackman, D. (2014) A guide to understanding social science research for natural scientists. Conservation Biology, 28, 1167-1177.

Nel, J.L., Roux, D.J., Driver, A., Hill, L., Maherry, A.C., SNADDON, K. et al. (2016) Knowledge co-production and boundary work to promote implementation of conservation plans. Conservation Biology, 30, 176-188.

O'Brien, K., Reams, J., Caspari, A., Dugmore, A., Faghihimani, M., FAZEY, I. et al. (2013) You say you want a revolution? Transforming education and capacity building in response to global change. Environmental Science \& Policy, 28, 48-59.

O’Rourke, M. \& Crowley, S.J. (2013) Philosophical intervention and cross-disciplinary science: the story of the toolbox project. Synthese, 190, 1937-1954.

Pooley, S.P., Mendelsohn, J.A. \& Milner-Gulland, E.J. (2014) Hunting down the chimera of multiple disciplinarity in conservation science. Conservation Biology, 28, 22-32.

Proctor, J.D. (1998) The social construction of nature: relativist accusations, pragmatist and critical realist responses. Annals of the Association of American Geographers, 88, 352-376.

Sandirook, C. (2015) What is conservation? Oryx, 49, 565-566.
Sandbrook, C., Adams, W.M., Búscher, B. \& Vira, B. (2013) Social research and biodiversity conservation. Conservation Biology, 27, 1487-1490.

Saunders, C.D., Brook, A.T. \& Eugene Myers, Jr, O. (2006) Using psychology to save biodiversity and human well-being. Conservation Biology, 20, 702-705.

Selinske, M.J., Garrard, G.E., Bekessy, S.A., Gordon, A., Kusmanoff, A.M. \& Fidler, F. (2018) Revisiting the promise of conservation psychology. Conservation Biology, 32, 1464-1468.

Sievanen, L., Campbell, L.M. \& Leslie, H.M. (2012) Challenges to interdisciplinary research in ecosystem-based management. Conservation Biology, 26, 315-323.

St John, F.A.V., Edward-Jones, G. \& Jones, J.P.G. (2010) Conservation and human behaviour: lessons from social psychology. Wildlife Research, 37, 648-667.

Sutherland, W.J., Shackelford, G. \& Rose, D.C. (2017) Collaborating with communities: co-production or co-assessment? Oryx, 51, 569-570.

Whatmore, S. (2002) Hybrid Geographies: Natures, Cultures, Spaces. Sage, London, UK. 